\title{
Commentary: Worldwide, the management of transposition may be more baffling than we knew
}

\author{
Jonathan M. Chen, MD
}

\author{
From the Division of Cardiothoracic Surgery, Children's Hospital of Philadelphia, Philadelphia, Pa. \\ Disclosures: Author has nothing to disclose with regard to commercial support. \\ Received for publication Sept 15, 2019; revisions received Sept 15, 2019; accepted for publication Sept 17, 2019; \\ available ahead of print Oct 23, 2019. \\ Address for reprints: Jonathan M. Chen, MD, Cardiothoracic Surgery, Children's Hospital of Philadelphia, 3401 \\ Civic Center Blvd, Suite 12NW10, Philadelphia, PA 19104 (E-mail: chenj14@email.chop.edu). \\ J Thorac Cardiovasc Surg 2020;159:251-2 \\ 0022-5223/\$36.00 \\ Copyright (C 2019 by The American Association for Thoracic Surgery \\ https://doi.org/10.1016/j.jtcvs.2019.09.110
}

The evolution from the atrial switch to the arterial switch operation may be the single example in congenital heart surgery most frequently cited to demonstrate surgical advancement from palliative to restorative. Although the concept of the arterial switch as "definitively corrective" may be debatable, irrefutably, during the past several decades, iterative improvements in technique have nearly eliminated the contributing morbidity of some of its most significant previous challenges (eg, coronary anomalies, associated lesions). Indeed, the persisting major risk factors for poor outcome are those less "modifiable" factors, of which late diagnosis after left ventricular "untraining" remains formidable, most notably in developing countries worldwide.

Globally, for those patients beyond the threshold to enjoy benefit from a rapid 2-stage arterial switch, the atrial switch (Senning or Mustard) still maintains prominence as an effective operative strategy. Because of this, as demonstrated by Hosny and colleagues ${ }^{1}$ in this issue of the Journal, the atrial switch still deserves continued focus and refinement in an effort to mitigate its well-known late complications (arrhythmia, baffle obstruction, exercise intolerance). From 2013 to 2018, the Aswan group managed 634 patients with transposition, 504 of whom underwent a 1stage arterial switch and 101 who underwent the Mustard procedure. Their technical modifications aim to maximize the alliterative triumvirate of the systemic venous bafflenamely, its capacitance, conduit, and contractile ("kick") functions. I encourage readers to review the linked videos describing these technical advances, as eloquently narrated by Dr Yacoub. ${ }^{1}$

Whereas previous reports have focused largely on tailoring the perfect Mustard pantaloon to prevent stenosis, the revisions described by Hosny and colleagues ${ }^{1}$ seek to "normalize" the mitral inflow, which they demonstrate by magnetic resonance imaging and have previously also shown by 3 - and 4-dimensional modeling. ${ }^{2-5}$ In addition, these modest alterations of the baffle suture line are hoped to preserve sinus node function and ideally limit later issues of arrhythmia. ${ }^{6}$ What remains to be demonstrated,

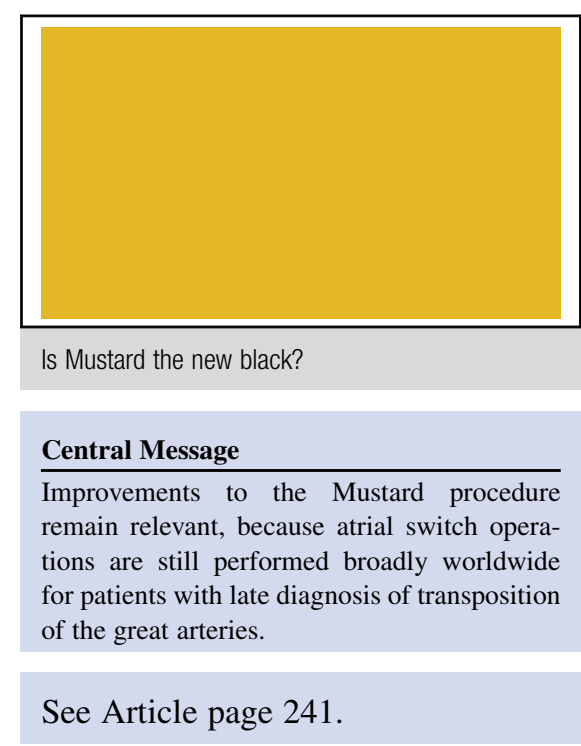

however, is whether the aggregate advantages of these technical modifications are offset by comparable issues of abnormal systemic right ventricular filling or-likely more daunting - the unrelenting march of systemic right ventricular decompensation with time. ${ }^{7,8}$ Indeed, also not yet verified with this technique is a correlated improvement in exercise capacity or hemodynamic response to exercise, which may in fact together represent the holy grail for the atrial switch if we accept at baseline our inability to halt the inexorable failure of the systemic right ventricle. ${ }^{9-11}$

Trainees today are taught reflexively to answer on board examinations that the atrial switch belongs in the graveyard of abandoned eponymous procedures-atriopulmonary Fontan, Baffes, Brock. The contribution of Hosny and colleagues, ${ }^{1}$ however, reminds us that the Mustard procedure cannot become a lost art. Indeed, whereas implementation of obstetrical screening guidelines boast a prenatal diagnosis of transposition approaching $80 \%$ in North America, the findings worldwide are far more sobering. ${ }^{12-14}$ We must acknowledge that for many developing countries, baffling as it seems, the atrial switch has never left the front page of Vogue. ${ }^{15}$ Until earlier diagnosis (and balloon atrial septostomy) is more broadly available worldwide, the tireless pursuit of perfection in the atrial switch will continue to represent a professional mandate.

\section{References}

1. Hosny H, Sedky Y, Romeih S, Simry W, Afifi A, Elsawy A, et al. Revival and modification of the Mustard operation. J Thorac Cardiovasc Surg. 2020;159: 241-9. 
2. Quaegebeur JM, Brom AG. The trousers-shaped baffle for use in the Mustard operation. Ann Thorac Surg. 1978;25:240-2.

3. Talwar S, Nair VV, Choudhary SK, Airan B. Atrial switch operation in the current era: modifications and pitfalls. World J Pediatr Congenit Heart Surg. 2012;3: 96-103.

4. Oelert H. Modification of the Mustard operation for surgical treatment of complete transposition by creating a confluence of the caval veins. Cardiol Young. 1991;1:71-9.

5. Aguib H, Chapron J, Donya M, Sedky Y, Hosny H, Yacoub M. 3D modelling of atrial and ventricular shape and function in a patient following the new modified Mustard operation. Glob Cardiol Sci Pract. 2015;2015:5.

6. El-Said GM, Gillette PC, Cooley DA, Mullins CE, McNamara DG. Protection of the sinus node in Mustard's operation. Circulation. 1976;53:788-91.

7. Cuypers JA, Eindhoven JA, Slager MA, Opić P, Utens EM, Helbing WA, et al. The natural and unnatural history of the Mustard procedure: long-term outcome up to 40 years. Eur Heart J. 2014;35:1666-74.

8. Derrick GP, Narang I, White PA, Kelleher A, Bush A, Penny DJ, et al. Failure of stroke volume augmentation during exercise and dobutamine stress is unrelated to load-independent indexes of right ventricular performance after the Mustard operation. Circulation. 2000;200(19 Suppl 3): III151-9.
9. Franzoso FD, Wohlmuth C, Greutmann M, Kellenberger CJ, Oxenius A, Voser EM, et al. Atrial function after the atrial switch operation for transposition of the great arteries: comparison with arterial switch and normal by cardiovascular magnetic resonance. Congenit Heart Dis. 2016;11:426-36.

10. Mathews RA, Fricker FJ, Beerman LB, Stephenson RJ, Fischer DR, Neches WH, et al. Exercise studies after the Mustard operation in transposition of the great arteries. Am J Cardiol. 1983;51:1526-9.

11. Kiener A, Kelleman M, McCracken C, Kochilas L, St Louis JD, Oster ME. Long term survival after arterial versus atrial switch in d-transposition of the great arteries. Ann Thorac Surg. 2018;106:1827-33.

12. Ravi P, Mills L, Fruitman D, Savard W, Colen T, Khoo N, et al. Population trends in prenatal diagnosis of transposition of the great arteries: impact of obstetric screening ultrasound guidelines. Ultrasound Obstet Gynecol. 2018;51:659-64.

13. van der Linde D, Konings EE, Slager MA, Witsenburg M, Helbing WA, Takkenberg JJ, et al. Birth prevalence of congenital heart disease worldwide: a systematic review and meta-analysis. J Am Coll Cardiol. 2011;58:2241-7.

14. Schidlow DN, Jenkins KJ, Gauveau K, Croti UA, Giang DTC, Konda RK, et al. Transposition of the great arteries in the developing world: surgery and outcomes. J Am Coll Cardiol. 2017;69:43-51.

15. Yacoub M, Hosny H, Afifi A. Surgery for TGA in developing countries: the end of the beginning. J Am Coll Cardiol. 2017;69:52-5. 